\title{
Erratum to: Factorizable inverse monoids
}

\author{
D.G. FitzGerald
}

Received: 23 September 2009 / Accepted: 18 December 2009 / Published online: 17 March 2010

(C) Springer Science+Business Media, LLC 2010

\section{Erratum to: Semigroup Forum \\ DOI 10.1007/s00233-009-9177-6}

At a late stage of preparation of his article, the author impetuously introduced an error into the last two sentences of Sect. 8.4, dealing with the Birget-Rhodes expansion $B R(G)$ of a group $G$. The maximal subgroup $H$ described there is actually a singleton $\{(1,\{1\})\}$, and so $H^{\downarrow}$ is a semilattice $\left\{(1, e) \in G \ltimes E^{f}: 1 \in e\right\}$-the idempotents of $B R(G)$. Of course, $B R(G)$ itself consists of all $(u, e) \in G \ltimes E^{f}$ such that $1, u \in e$.

Communicated by Norman R. Reilly.

The online version of the original article can be found under doi:10.1007/s00233-009-9177-6.

D.G. FitzGerald $(\bowtie)$

School of Mathematics and Physics, University of Tasmania, Private Bag 37, Hobart 7001, Australia e-mail: D.FitzGerald@utas.edu.au 